\title{
Anterior abdominal wall defects
}

\author{
P M LAFFERTY, A J EMMERSON, P J FLEMING, J D FRANK, AND H R NOBLETT \\ Department of Child Health, Bristol Maternity Hospital
}

SUMmaRY A total of 48 infants with abdominal wall defects referred to the South West Regional Neonatal Surgical Centre over a period of six years were reviewed. There were $27(56 \%)$ infants with gastroschisis and $21(44 \%)$ infants with exomphalos. At the regional centre, four pregnancies with gastroschisis were terminated following a prenatal diagnosis, one child was stillborn, and one with exomphalos and trisomy 13 died soon after birth. Of the remaining 42 live births, the one year survival for babies born with a gastroschisis was $95 \%(21 / 22)$ and with an exomphalos was $81 \%(17 / 20)$. All deaths, except one, were due to factors other than the abdominal defect. The effect on outcome of prenatal diagnosis, parental counselling, in utero transfer, mode of delivery, and methods of surgical closure was reviewed.

The management of infants with gastroschisis or exomphalos presents problems to neonatologists, paediatric surgeons, and obstetricians. Since their recognition in the early 1960 s as distinct entities there has been a progressive improvement in survival. ${ }^{12}$ With the more frequent ultrasonographic diagnosis of these defects, knowledge of the long term outlook is of utmost importance when conselling parents on the question of termination. If the pregnancy continues, the place, time, and mode of delivery need to be planned and the postnatal management discussed with the parents.

\section{Patients and methods}

Obstetric, paediatric, and ultrasound records were reviewed for all 48 infants with abdominal wall defects referred to the South West Regional Neonatal Surgical Centre during the period 1981 to 1986 inclusive. Follow up on all surviving infants was for between one and six years. Precise termination statistics were only available for the Bristol Maternity Hospital.

\section{Results}

Six of the 48 cases originally booked for antenatal care at the Bristol Maternity Hospital. All received prenatal ultrasonography and the diagnosis of an abdominal wall defect was made in five $(83 \%)$ (mean gestational age 17.8 weeks, range 17-19). Four of these mothers subsequently elected for termination of pregnancy; all four fetuses had the gastroschisis defect. The remaining infant with an in utero diagnosis of gastroschisis died as an unexpected stillbirth at 37 weeks. The sixth child, with trisomy 13 and exomphalos, which was not detected antenatally, died soon after birth without active treatment being offered.

Of the remaining 42 live births who originally booked for antenatal care in district general hospitals outside Bristol, $26(61 \%)$ had recorded evidence of prenatal ultrasonography and the diagnosis of anterior abdominal wall defect was made in nine $(34.6 \%)$ (mean gestational age 20.7 weeks, range 12-35). Details of the prenatal ultrasound studies are shown in table 1 . Subsequently six children in

Table 1 Details of prenatal ultrasound

\begin{tabular}{|c|c|c|c|c|c|}
\hline & $\begin{array}{l}\text { No of } \\
\text { infants }\end{array}$ & $\begin{array}{l}\text { No }(\%) \text { with } \\
\text { ultrasonography } \\
\text { recorded }\end{array}$ & $\begin{array}{l}\text { No (\%) } \\
\text { with } \\
\text { positive } \\
\text { scan }\end{array}$ & $\begin{array}{l}\text { Detection rate } \\
(\text { No }(\%) \\
\text { of total })\end{array}$ & $\begin{array}{l}\text { Mean (range) } \\
\text { gestational } \\
\text { age (weeks) }\end{array}$ \\
\hline $\begin{array}{l}\text { Total } \\
\text { Booked at: }\end{array}$ & 48 & $32 \quad(66)$ & $14(43)$ & $14(29)$ & $22 \cdot 6(16-36)$ \\
\hline Bristol & 6 & $6(100)$ & $5(83)$ & $5(83)$ & $17 \cdot 8(17-19)$ \\
\hline District general hospital & 42 & $26(62)$ & $9(34)$ & $9(21)$ & $20 \cdot 7(12-35)$ \\
\hline
\end{tabular}


Table 2 Comparative perinatal data

\begin{tabular}{|c|c|c|}
\hline & $\begin{array}{l}\text { Gastroschisis } \\
(n=27)\end{array}$ & $\begin{array}{l}\text { Exomphalos } \\
(n=21)\end{array}$ \\
\hline Maternal age (years) & $22 \cdot 6$ & $26 \cdot 5$ \\
\hline \multicolumn{3}{|l|}{ Parity (No (\%)) } \\
\hline Primipara & $19(70)$ & $9(42)$ \\
\hline Multipara & $8(29)$ & $12(58)$ \\
\hline Mean (range) gestational age (weeks) & $37 \cdot 2(33 \cdot 5-40 \cdot 0)$ & $36 \cdot 8(30 \cdot 0-40 \cdot 0)$ \\
\hline Mean (range) birth weight (g) & $2400(1460-3520)$ & $2800(1590-4140)$ \\
\hline Mean (range) Apgar score at 5 minutes & $8 \cdot 3(10 \cdot 0-4 \cdot 0)$ & $8 \cdot 6(4 \cdot 0-10 \cdot 0)$ \\
\hline Mean (range) serum albumin $(g / l)$ & $26 \cdot 4(21 \cdot 0-37 \cdot 0)$ & $28 \cdot 0(20 \cdot 0-35 \cdot 0)$ \\
\hline \multicolumn{3}{|l|}{ Delivery $(\text { No }(\%))^{*}$} \\
\hline Vaginal & $14(61)$ & $15(72)$ \\
\hline Caesarean & $7(30)$ & $6(28)$ \\
\hline Forceps & $2(9)$ & \\
\hline \multicolumn{3}{|l|}{ Surgical treatment $($ No $(\%)) \dagger$} \\
\hline Primary closure & $12(55)$ & $9(45)$ \\
\hline Delayed/silo (gastroschisis) or serial (exomphalos) & $10(45)$ & $11(55)$ \\
\hline \multicolumn{3}{|l|}{ Mean (range) weight (kg) $\dagger$} \\
\hline At 6 months & $5 \cdot 9(3 \cdot 8-8 \cdot 5)$ & $6 \cdot 6(4 \cdot 2-8 \cdot 1)$ \\
\hline At 1 year & $8 \cdot 1(5 \cdot 8-10 \cdot 3)$ & $9 \cdot 4(7 \cdot 2-11 \cdot 1)$ \\
\hline \multicolumn{3}{|l|}{ Survival $($ No $(\%)) \dagger$} \\
\hline At 6 months & $21(95)$ & $18(86)$ \\
\hline At 1 year & $21(95)$ & $17(81)$ \\
\hline
\end{tabular}

${ }^{*}$ For gastroschisis $n=23$ as four pregnancies were terminated. $†$ For gastroschisis $n=22$ as one infant was stillborn; for exomphalos $n=20$ as one infant died soon after birth.

Table 3 Associated anomalies in anterior abdominal wall defects, Bristol 1981-6

\begin{tabular}{|c|c|c|}
\hline & Gastroschisis & Exomphalos \\
\hline \multicolumn{3}{|l|}{ Cardiac: } \\
\hline $\begin{array}{l}\text { Total anomalous pulmonary } \\
\text { venous drainage }\end{array}$ & 0 & 1 \\
\hline Pulmonary artery hypoplasia & 0 & 2 \\
\hline Major septal defects & 0 & 1 \\
\hline Patent ductus arteriosus & 2 & 2 \\
\hline Persistent fetal circulation & 0 & 1 \\
\hline Total (\%) & $2(9)$ & $7(33)$ \\
\hline \multicolumn{3}{|l|}{ Gastrointestinal: } \\
\hline Persistent vitellointestinal duct & 1 & 1 \\
\hline Meckel's diverticulum & 0 & 1 \\
\hline Ileal atresia & 1 & 1 \\
\hline Morgagni defect & 0 & 1 \\
\hline Rectal atresia & 1 & - \\
\hline Colonic atresia & 1 & - \\
\hline Total (\%) & $4(18)$ & $4(20)$ \\
\hline \multicolumn{3}{|l|}{ Other: } \\
\hline Undescended testis & 2 & 0 \\
\hline Hemihypertrophy & 1 & 0 \\
\hline Lissencephaly & 1 & 0 \\
\hline Congenital dislocated hip & 1 & 1 \\
\hline Hypospadias & 0 & 1 \\
\hline Beckwith's syndrome & 0 & 5 \\
\hline Cystic kidney & 0 & 1 \\
\hline Trisomy 13 & 0 & 1 \\
\hline Total (\%) & $5(23)$ & $9(45)$ \\
\hline
\end{tabular}

this group were transferred in utero to the regional centre and all survived; the remaining three were transferred after birth, with one death resulting from problems in transit.

Comparative perinatal data for the two groups are shown in table 2.

\section{GASTROSCHISIS}

No major cardiac anomalies were found in the 22 liveborn infants in this group, though two had a symptomatic patent ductus arteriosus. Fetal pathological examination in five cases (four terminations and one stillbirth) showed no major cardiac anomaly. Four infants $(18 \%)$, however, had associated gastrointestinal anomalies, all amenable to corrective surgery (see table 3 ). The well documented motility and malabsorption problems associated with gastroschisis ${ }^{3}$ were reflected in the median nude weights at 6 months and 1 year of age, which were at or below the 3 rd centile. Survival in this group was excellent at $95 \%$ at 1 year of age, the only death being the one attributable to problems in transfer (table 2).

\section{EXOMPHALOS}

By comparison the group of infants with exomphalos provided more troublesome management problems. Of 20 infants only nine $(45 \%)$ were amenable to primary closure; prosthetic Dexon sheets were used in five of these infants. 
Associated cardiac anomalies were found in seven $(33 \%)$ infants with exomphalos, although none of these defects were detected prenatally. Three of the four deaths in the group with exomphalos were due to major cardiac defects in the children who received prenatal ultrasonography (mean gestational age 17 weeks) without detection of either exomphalos or cardiac anomaly.

In four $(20 \%)$ of infants with exomphalos there were associated gastrointestinal anomalies that did not directly affect the mortality (see table 3 ).

Survival rates in this group were $86 \%$ at 6 months and $81 \%$ at 1 year of age; only one child died as a direct result of the abdominal defect-from fulminating septicaemia associated with the use of a prosthetic silo sac. In contrast with the group with gastroschisis the median nude weights at 6 months and 1 year of age were at or above the 10th centile (table 2).

\section{Discussion}

With a recorded incidence of 1:2550 pregnancies children with anterior abdominal wall defects are not an uncommon management problem, especially in regional referral centres. ${ }^{4} \mathrm{~A}$ vast improvement in survival statistics since the early 1960 s has been attributable to improved neonatal intensive care overall $^{5}$; in this series it is over $80 \%$ at one year.

We report a prenatal detection rate of only $29 \%$ overall in our series. The percentage of positive scans in the regional centre and district general hospitals were $83 \%$ and $34 \%$ respectively $(p<0.01)$. One major value of prenatal ultrasound detection of abdominal wall defects is that it may allow thorough investigation for the presence of cardiac or chromosomal abnormalities in fetuses with exomphalos.
None of the associated major cardiac defects were diagnosed antenatally, however, and these were responsible for three of the four deaths in the group with exomphalos. The outlook for infants with exomphalos without these associated abnormalities, and for all infants with gastroschisis, is very good in terms of survival and development; thus in future parents may be less likely to opt for termination of pregnancy. Such infants should be delivered at a regional centre whenever possible to avoid the problems of postnatal transfer. The mode and timing of delivery should be determined by obstetric indications. In this series there appears to be no advantages in elective caesarean section for infants with gastroschisis or exomphalos; however, a prospective randomised trial is necessary. Wherever possible primary closure of the defect should be the rule, using prosthetic inlay grafts and primary skin cover as a suitable alternative. Should postnatal transfer be necessary it is suggested the infant be stabilised before transfer to the regional centre.

\section{References}

1 Moore TC. Gastroschisis and omphalocele: clinical differences. Surgery 1977;82:561-8.

2 Knutrud O, Bjordal RI, Ro J, Bo G. Gastroschisis and omphalocele. Progress in Pediatric Surgery 1979;13:51-61.

3 Cywes S, Davies MR. Complications and follow up at gastroschisis. S Afr Med J 1979;55:499-501.

${ }^{4}$ Mann L, Ferguson-Smith MA, Desai M, Gibson AA, Raine PA. Prenatal assessment of anterior abdominal wall defects and their prognosis. Prenat Diagn 1984;4:427-35.

5 Schwaitzberg SD, Pokorny WJ, McGill CW, Harberg FJ. Gastroschisis and omphalocele. Am J Surg 1982;144:650-4.

Correspondence to Mr PM Lafferty, Department of Paediatric Surgery, Western General Hospital, Crewe Road, Edinburgh EH4 2XU.

Accepted 27 January 1989 